\title{
Endoscopic management of bleeding Dieulafoy-like lesion at hepaticojejunal anastomosis
}

This case describes a 64-year-old man with a history of total pancreatectomy, duodenectomy, and total gastrectomy for pancreatic cancer. He previously underwent reconstruction with esophagojejunal anastomosis and hepaticojejunal anastomosis, without Roux-en-Y. Arterial bridges of the superior mesenteric artery and the celiac trunk were performed, for which he received permanent antiplatelet therapy; he also uses oral anticoagulants to treat a deep vein thrombosis of the right upper extremity related to a central venous catheter. The patient presented with melena and acute anemia. Computed tomography angiography showed dense content in the small bowel with no evidence of active bleeding. It was decided to do an upper endoscopy ( Video 1 ).

In the mucosa surrounding the hepaticojejunal anastomosis, three vascular lesions were observed ( $\triangleright$ Fig. 1 a), with enhanced visualization achieved with linked color imaging ( $\triangleright$ Fig. $\mathbf{1 b}$ ) and blue laser

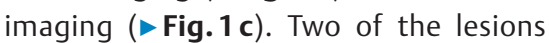
were compatible with angioectasias, and the third was compatible with a cirsoid aneurysm, which presented a visible vessel with red stigmata.

It was decided to treat the lesion with argon plasma coagulation (APC), which caused active bleeding. Two clips were placed to achieve hemostasis. More clips were placed on the surrounding mucosa to treat the arteriolar vessels causing the

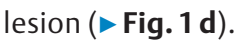

The patient recovered with no new episodes of gastrointestinal bleeding, and was discharged on the third day.

Dieulafoy's lesions in the jejunum are rare (1\%) [1]. In this case, there was doubt about the origin of the lesion; it could have been related to neoformation of blood vessels or varicose veins [2].

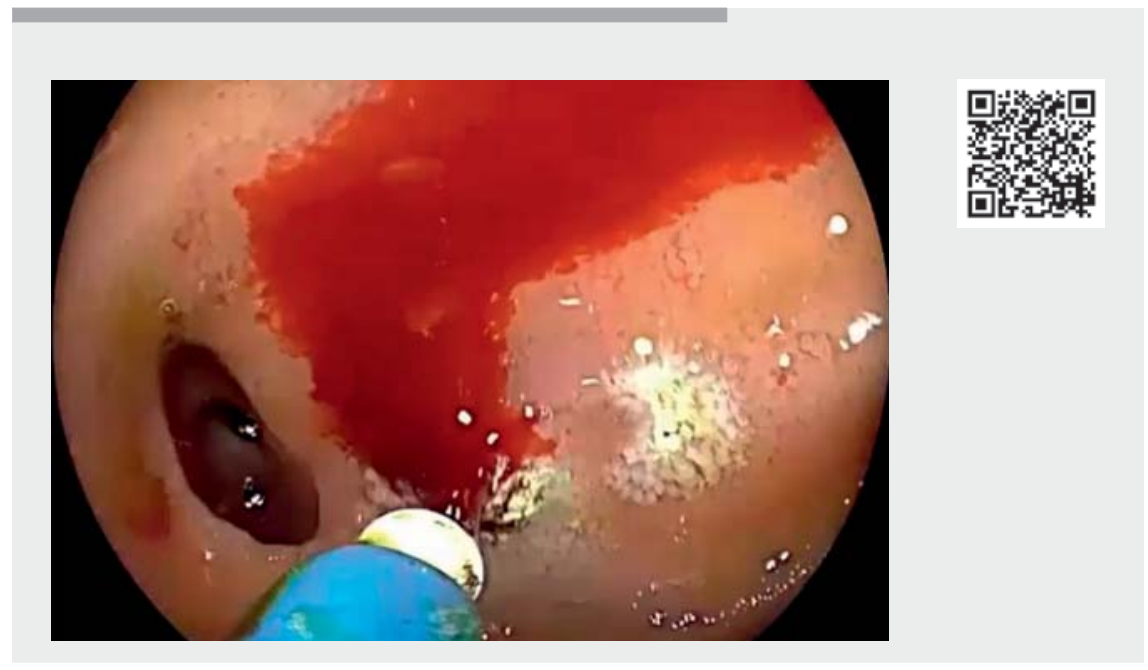

$\checkmark$ Video 1 Endoscopic management of jejunal hemorrhage.
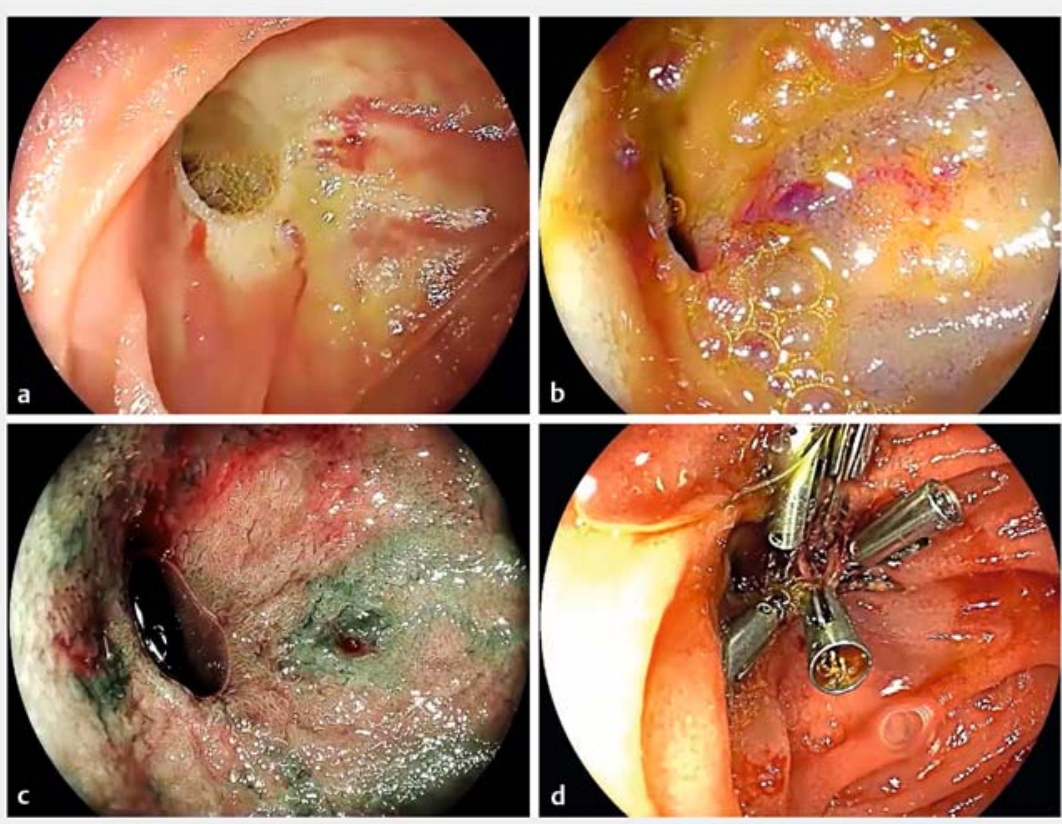

- Fig. 1 Endoscopic views of the hepaticojejunal anastomosis showing perianastomotic neoformation of blood vessels. a White-light mode. b Linked color imaging mode. $\mathbf{c}$ Blue laser imaging mode. $\mathbf{d}$ Hemoclip placement to the perianastomotic newly formed blood vessels and their tributaries. 
Diagnosis and treatment can be performed endoscopically in most cases [3], and a lower rate of rebleeding has been reported using combined endoscopic therapies [4]. Use of APC to treat angiodysplasia around the hepaticojejunal anastomosis has been reported previously [5].

Endoscopy_UCTN_Code_CCL_1AZ_2AO

\section{Competing interests}

The authors declare that they have no conflict of interest.

The authors

Sergio Rubel Cohen ${ }^{1,2}$, Raúl Araya Jofré ${ }^{1}$, Gino Baccigaluppi Méndez ${ }^{1}$, César Acevedo Sylvester ${ }^{2}$

1 Clínica Universidad de los Andes, Santiago, Chile

2 Centro Endoscópico Diagnóstico y terapéutico (CEDIT), Barros Luco Trudeau Hospital, Santiago, Chile
Corresponding author

\section{Sergio Rubel Cohen}

Centro Endoscópico Diagnóstico y terapéutico (CEDIT), Hospital Barros Luco Trudeau, Gran Avenida Jose Miguel Carrera 3204, Santiago, San Miguel, Región Metropolitana, Santiago de Chile 8900085 , Chile

sergiorubelc@gmail.com

\section{References}

[1] Kozan R, Gülen M, Yılmaz T et al. Massive lower gastrointestinal bleeding from a jejunal Dieulafoy lesion. Ulus Cerrahi Derg 2014; 30: 225-227

[2] Kantartzis M, Usmiani ], Lersmacher J et al. [Massive gastrointestinal hemorrhage from a hepaticojejunostomy in pancreatogenic mesenteric vein thrombosis. Diagnosis and therapy] [article in German]. Langenbecks Arch Chir 1992; 377: 141-143

[3] Dulic-Lakovic E, Dulic M, Hubner D et al. Bleeding Dieulafoy lesions of the small bowel: a systematic study on the epidemiology and efficacy of enteroscopic treatment. Gastrointest Endosc 2011; 74: 573-580

[4] Kanth R, Mali P, Roy P. Outcomes in Dieulafoy's lesion: a 10-year clinical review. Dig Dis Sci 2015; 60: 2097-2103

[5] Neumann H, Mönkemüller K, Malfertheiner P. Obscure overt GI bleeding secondary to angiodysplasias at the hepaticojejunostomy diagnosed and successfully treated with double-balloon enteroscopy. Gastrointest Endosc 2008; 67: 563-565
Bibliography

Endoscopy 2022; 54: E626-E627

DOI 10.1055/a-1711-3960

ISSN 0013-726X

published online 4.2.2022

(c) 2022. Thieme. All rights reserved.

Georg Thieme Verlag KG, Rüdigerstraße 14,

70469 Stuttgart, Germany

ENDOSCOPY E-VIDEOS

https://eref.thieme.de/e-videos

回屌 Endoscopy E-Videos is an Fy open access online section, 回解: reporting on interesting cases and new techniques in gastroenterological endoscopy. All papers include a high quality video and all contributions are freely accessible online. Processing charges apply (currently EUR 375), discounts and wavers acc. to HINARI are available.

This section has its own submission website at https://mc.manuscriptcentral.com/e-videos 